\title{
Ruminal and blood responses to propylene glycol during frequent feeding
}

\author{
Y.-H. Chung, C. M. Martinez, N. E. Brown, T. W. Cassidy, and G. A. Varga ${ }^{1}$ \\ Department of Dairy and Animal Science, The Pennsylvania State University, University Park 16802
}

\begin{abstract}
The objective of the current experiment was to study the responses of ruminal and blood metabolites of Holstein dairy cows to propylene glycol (PG) under different methods of delivery during frequent feeding. By providing the same amount $(200 \mathrm{~mL}$ or $200 \mathrm{~g})$ of PG, delivery methods for PG were assessed: 1) control treatment: no PG; 2) dietary treatment: $200 \mathrm{~g}$ of PG as a dry product ( $65 \%$ purity; corresponded to $308 \mathrm{~g}$ of the dry product) mixed into the TMR; 3) oral-drench treatment: $200 \mathrm{~mL}$ of liquid PG (100\% purity) orally drenched; and 4) rumen-drench treatment: $200 \mathrm{~g}$ of PG as a dry product drenched via the rumen cannula to mimic top dressing. Eight multiparous (lactation $=3$ $\pm 1.1 \mathrm{SD}$ ) ruminally cannulated Holstein dairy cows $(\mathrm{DIM}=204 \pm 104.5 \mathrm{SD})$ were fed $\mathrm{PG}$ for $4 \mathrm{~d}(\mathrm{~d} 11$ to 14 ) in a replicated $4 \times 4$ Latin square design with an experimental length of $14 \mathrm{~d}$ for each period. On the last day of each period, serial blood samples were removed from an indwelling catheter placed in the right jugular vein immediately before and for $4 \mathrm{~h}$ after $\mathrm{PG}$ administration. Cows were fed at $12 \times$ feeding/d for $2 \mathrm{~d}$ before entering the serial sampling period to minimize postprandial influences on blood metabolites. Ruminal content was also sampled hourly for $4 \mathrm{~h}$ on $\mathrm{d} 14$. Milk was sampled from 2 consecutive milkings on d 13 during each period. Dry matter intake and milk yield were not affected by PG. Percentages of milk lactose were increased by $\mathrm{PG}$ delivered by all methods tested in the current experiment. Ruminal concentrations (as percentages of total volatile fatty acids) of acetate were decreased and concentrations of propionate and isovalerate were increased by PG, regardless of the delivery method; however, total volatile fatty acid concentration was not affected by PG. Ruminal concentrations of butyrate were decreased and concentrations of valerate were increased by PG drench, via either an oral or ruminal drench. The degree of reduction in butyrate concentration or increase in valerate concentration was affected by PG dose. Serum insulin peaked more rapidly
\end{abstract}

Received February 15, 2009.

Accepted May 21, 2009.

${ }^{1}$ Corresponding author: gvarga@psu.edu and at a greater concentration for cows receiving $\mathrm{PG}$ via drenching, but not when $\mathrm{PG}$ was provided as a part of the TMR. Plasma glucose, however, tended to peak more rapidly at a greater concentration for cows receiving $\mathrm{PG}$, regardless of the delivery method. Propylene glycol for the amount drenched (orally or ruminally) or fed (incorporated into the ration) shifted ruminal fermentation toward a more glucogenic environment. Drenching demonstrated a better efficacy than feeding PG because of the amount of PG that was available to the animal at the time of sampling. Effects of drenching dry PG into the rumen were comparable with orally drenching liquid PG.

Key words: propylene glycol, ruminal fermentation, plasma glucose, serum insulin

\section{INTRODUCTION}

Propylene glycol (PG) via drenching or feeding was demonstrated by Johnson (1954) to treat ketosis effectively in dairy cows because of its glucogenic property (Hanzlik et al., 1939). Propylene glycol has been shown to increase the concentration of propionate and decrease the ratio of acetate to propionate, thereby resulting in a ruminal VFA pattern that is more glucogenic (Clapperton and Czerkawski, 1972; Czerkawski and Breckenridge, 1972). Supplementation of PG to cows has been shown to increase blood insulin and glucose concentrations (Studer et al., 1993; Grummer et al., 1994; Christensen et al., 1997). A drench dose of approximately $500 \mathrm{~mL} / \mathrm{d}$ or more is often used as a prophylactic treatment for clinical ketosis in dairy cows (Herdt and Emery, 1992). A lower amount of PG (e.g., $118 \mathrm{~mL} / \mathrm{d}$ ), however, is often drenched to cows after parturition as a preventive for subclinical ketosis. Replacing routine drenching with feeding can reduce stress on the cow and on the person who does the drenching, reduce the cost of labor, and ultimately improve the overall health and production of dairy cows. Results from our previous experiments (Chung et al., 2009a,b) showed that supplementing $162.5 \mathrm{~g} / \mathrm{d}$ (as a preventive dose) of PG either as a top dressing or as a part of the TMR (by mixing PG into the TMR) reduced plasma BHBA concentrations without changing serum insulin and plasma glucose. Bassett (1975) suggested that the 
magnitude of the response in blood insulin concentration is highly dependent on the amount of food ingested. Armentano et al. (1984) reported that cattle fed $12 \times$ feeding/d were in a steady state for glucose production and utilization. Therefore, to minimize postprandial effects on blood insulin and glucose responses to PG, a $12 \times$ feeding/d frequent feeding schedule was used in the current experiment. Opportunities exist for a dry form of PG to be fed or drenched to cows. A dry form of $P G$ is easier to store on the farm and maintains the consistency of the diet if it is top dressed or mixed into the ration compared with $\mathrm{PG}$ in liquid form. It was hypothesized that a dry form of PG provided as a top dressing would be as effective as liquid PG provided as a drench in stimulating blood insulin and glucose responses. To ensure complete consumption of dry PG by cows, dry PG was ruminally drenched. The objectives of the current experiment were to study the effects of PG, as a dry product, via different methods of delivery on serum insulin and plasma glucose concentrations and ruminal VFA patterns for cows during frequent feeding.

\section{MATERIALS AND METHODS}

\section{Experimental Design, Animal Care, and Treatments}

This experiment was conducted under the approval of The Pennsylvania State University Animal Care and Use Committee. Eight multiparous (lactation $=3 \pm 1.1$ SD) ruminally cannulated Holstein dairy cows (average $\mathrm{DIM}=204 \pm 104.5 \mathrm{SD}$ ) were allocated into 2 groups and used in a $4 \times 4$ Latin square design ( 2 replications) to study responses of ruminal and blood metabolites of Holstein dairy cows to PG under different methods of delivery. Allocation of cows was balanced for lactation number, predicted 305-d mature equivalent milk production for the current lactation, DIM, BW, feed intake, and milk yield and composition from the previous DHI testing result. Cows were housed in a tunnel-ventilated tie-stall barn located at the Pennsylvania State University Dairy Research and Education Center (University Park, PA). Cows were moved into this facility at least 1 wk before the initiation of the experiment.

The experiment consisted of 4 periods of $14 \mathrm{~d}$ each, with the last day (d 14) as the serial blood and ruminal sample collection day. During each experimental period, d 1 to 9 was the adaptation period, during which cows were milked twice daily at approximately 0630 and $1830 \mathrm{~h}$ and fed a basal lactating cow diet as a TMR (Table 1) once daily at approximately $0800 \mathrm{~h}$ after the morning milking. The TMR was formulated based on NRC (2001) guidelines for Holstein dairy cows at 660 $\mathrm{kg}$ of BW and producing $41 \mathrm{~kg}$ of milk/d with $3.7 \%$ of milk fat. Cows had access to an open dry lot for 2 $\mathrm{h}$ before each milking. Days 11 to 14 of each experimental period was the treatment period, during which treatments were administrated and cows were gradually adapted to a frequent feeding schedule to minimize postprandial influences attributable to feeding. During the treatment period, cows were milked at 0500 and $1700 \mathrm{~h}$ and brought back to the tie-stall barn directly from the milking parlor after each milking.

By providing the same amount $(200 \mathrm{~mL}$ or $200 \mathrm{~g} / \mathrm{cow}$ per day) of PG, delivery methods for PG were assessed: 1) control treatment: no PG; 2) dietary treatment: 200 $\mathrm{g} / \mathrm{d}$ of $\mathrm{PG}$ as a dry product (65\% purity; corresponded to $308 \mathrm{~g}$ of the dry product) mixed into the TMR; 3 ) oral-drench treatment: $200 \mathrm{~mL} / \mathrm{d}$ of liquid PG $(100 \%$ purity) drenched orally by using a 200-mL drench gun (Nasco, Fort Atkinson, WI); and (4) rumen-drench treatment: $200 \mathrm{~g} / \mathrm{d}$ of PG as a dry product drenched via the rumen cannula. For the rumen-drench treatment, dry PG was first dissolved into $500 \mathrm{~mL}$ of $38^{\circ} \mathrm{C}$ distilled water and drenched into the cavity of the reticulum via the rumen cannula by using a tubing connected to a funnel. The tubing and funnel were rinsed with $250 \mathrm{~mL}$ of $38^{\circ} \mathrm{C}$ distilled water to remove any residue. Ruminal drenching was completed within 3 to 5 min. Cows on the control treatment were not drenched or provided PG in the diet. The liquid PG used contained $99.9 \%$ of PG. The dry PG used was a nonacidogenic dry product (Gly-Tran 65, NutriLinx, LLC, Montpelier, VT; $\mathrm{NE}_{\mathrm{L}}=$ $2.6 \mathrm{Mcal} / \mathrm{kg}$ ) that was composed of $65 \% \mathrm{PG}$ and $35 \%$ silicon dioxide as the carrier.

\section{Frequent Feeding}

Starting at $1000 \mathrm{~h}$ on d 10, one day before the start of each experimental treatment period, cows were gradually adapted to a frequent feeding schedule at $6 \times, 6 \times$, $12 \times, 12 \times$, and $12 \times$ feeding/d on d 10, 11, 12, 13, and 14 , respectively. Cows were fed at $12 \times$ feeding/d for 2 $\mathrm{d}$ before entering the serial sampling period on $\mathrm{d} 14$. The basal lactating cow TMR fed to each cow was weighed into smaller equal portions and fed frequently to each cow. Feed refusals from the previous day were weighed and the amount of feed offered was adjusted daily to allow a $10 \%$ refusal. Feed was pushed up to cows approximately 4 to 6 times per day. Treatments were administrated accordingly immediately after the first feeding of fresh feed. After the conclusion of the serial sampling period at $1400 \mathrm{~h}$ on the last day of each experimental period, feed refusals were weighed and cows were returned to $1 \times$ feeding/d. 
Table 1. Ingredient and chemical composition (means \pm SD) of the basal lactating cow TMR

\begin{tabular}{|c|c|}
\hline Item & Amount \\
\hline \multicolumn{2}{|l|}{ Ingredient composition, $\%$ of dietary DM } \\
\hline Corn silage & $34.8 \pm 0.01$ \\
\hline Alfalfa haylage & $14.6 \pm 0.01$ \\
\hline Alfalfa hay & $3.2 \pm 0.00$ \\
\hline Cottonseed hulls & $6.4 \pm 0.00$ \\
\hline Soybeans, roasted & $9.3 \pm 0.84$ \\
\hline Corn, ground & $8.3 \pm 1.20$ \\
\hline Canola meal & $6.4 \pm 0.00$ \\
\hline Soybeans, ${ }^{1}$ heat treated & $2.6 \pm 0.38$ \\
\hline Bakery by-product, ${ }^{2}$ dried & $5.2 \pm 0.41$ \\
\hline Molasses, liquid & $4.5 \pm 0.06$ \\
\hline Bicarbonate, bentonite, and mineral and vitamin premix ${ }^{3}$ & $4.8 \pm 0.00$ \\
\hline \multicolumn{2}{|l|}{ Chemical composition } \\
\hline $\mathrm{DM}, \%$ & $48.5 \pm 1.70$ \\
\hline $\mathrm{CP}, \%$ of $\mathrm{DM}$ & $16.2 \pm 0.51$ \\
\hline Soluble CP, $\%$ of DM & $6.6 \pm 0.53$ \\
\hline $\mathrm{ADF}, \%$ of $\mathrm{DM}$ & $22.0 \pm 1.16$ \\
\hline $\mathrm{NDF}, \%$ of DM & $32.7 \pm 1.45$ \\
\hline Fat, $\%$ of DM & $4.6 \pm 0.38$ \\
\hline Total digestible nutrients, $\%$ of DM & $70.4 \pm 0.53$ \\
\hline $\mathrm{NE}_{\mathrm{L}},{ }^{4} \mathrm{Mcal} / \mathrm{kg}$ & $1.6 \pm 0.01$ \\
\hline Ash, \% of DM & $8.6 \pm 0.58$ \\
\hline $\mathrm{Ca}, \%$ of DM & $1.2 \pm 0.12$ \\
\hline $\mathrm{P}, \%$ of $\mathrm{DM}$ & $0.4 \pm 0.01$ \\
\hline $\mathrm{Mg}, \%$ of $\mathrm{DM}$ & $0.3 \pm 0.01$ \\
\hline $\mathrm{K}, \%$ of DM & $1.6 \pm 0.06$ \\
\hline $\mathrm{Na}, \%$ of $\mathrm{DM}$ & $0.5 \pm 0.03$ \\
\hline $\mathrm{Fe}, \mathrm{mg} / \mathrm{kg}$ & $326.3 \pm 58.65$ \\
\hline $\mathrm{Mn}, \mathrm{mg} / \mathrm{kg}$ & $85.1 \pm 5.84$ \\
\hline $\mathrm{Zn}, \mathrm{mg} / \mathrm{kg}$ & $103.0 \pm 6.75$ \\
\hline $\mathrm{Cu}, \mathrm{mg} / \mathrm{kg}$ & $20.7 \pm 1.99$ \\
\hline
\end{tabular}

${ }^{1}$ AminoPlus (Ag Processing Inc., Omaha, NE).

${ }^{2}$ Cookie meal.

${ }^{3}$ Mineral and vitamin premix contained $0.3 \%$ of S, $7.2 \mathrm{mg} / \mathrm{kg}$ of Se, $4.7 \mathrm{mg} / \mathrm{kg}$ of Co, $11.8 \mathrm{mg} / \mathrm{kg}$ of I, $21.1 \mathrm{mg} /$ $\mathrm{kg}$ of vitamin A, $438.6 \mu \mathrm{g} / \mathrm{kg}$ of vitamin D, and $685.9 \mathrm{mg} / \mathrm{kg}$ of vitamin E.

${ }^{4}$ Estimated based on NRC (2001).

\section{Jugular Catheterization and Serial Blood and Ruminal Content Sampling}

On the last day (d 14) of each experimental period at approximately $1 \mathrm{~h}$ before the administration of treatments, an indwelling catheter (Abbocath- $\mathrm{T}$, 16-gauge $\times 140 \mathrm{~mm}, 180 \mathrm{~mL} / \mathrm{min} ;$ Abbott Ireland, Sligo, Ireland) was placed in the external right jugular vein of each cow. A 60 -mm length of extension tubing (Cook Inc., Bloomington, IN) connected the indwelling catheter to an injection plug (Surflo SR TP2, 0.16-mL volume; Terumo Medical Corp, Elkton, MD) for blood withdrawal. Catheters and extension tubings were filled with heparinized saline (250 $\mathrm{IU} / \mathrm{mL}$ of isotonic saline) after every blood sample to maintain patency. Serial blood samples were collected immediately before (designated as baseline; collected at $-5 \min \pm 3 \mathrm{SD}$ for the oral-drench group and at -6 min $\pm 2 \mathrm{SD}$ for all other treatment groups) and immediately after (designated as time 0 ) the administration of treatments and again at 10, 20, 30, 40, 50,60, 80, 100, 120, 140, 160,
180, 200, 220, and 240 min after the administration of treatments. Fifteen milliliters of blood was withdrawn each time and transferred into evacuated tubes (Becton Dickinson, Rutherford, NJ). Blood tubes for plasma collection were stored on ice before further processing. Plasma was separated from whole blood by centrifuging blood tubes at 3,000 $\times g$ for 15 min at $4^{\circ} \mathrm{C}$, within $1 \mathrm{~h}$ after collection. Blood tubes for serum collection were allowed to sit for approximately $0.5 \mathrm{~h}$ and centrifuged at $1,000 \times g$ for $15 \mathrm{~min}$ at room temperature to separate serum from whole blood. Plasma and serum were recovered and stored at $-20^{\circ} \mathrm{C}$ until analysis of concentrations for glucose and insulin, respectively. Blood tubes for plasma collection contained potassium oxalate and $4 \%$ sodium fluoride. Blood tubes (serum separator tubes) for serum collection contained a clot activator (polymer gel with silica activator).

Ruminal contents were collected via the rumen cannula from the dorsal, ventral, and caudal areas in the rumen at $60,120,180$, and 240 min after the administration of treatments (on d 14). Ruminal contents 
were thoroughly mixed by hand, and ruminal fluid was squeezed and filtered through 4 layers of cheesecloth. The filtrate was immediately measured for $\mathrm{pH}(\mathrm{pH}$ meter, model M90; Corning Inc., Corning, NY), and $15 \mathrm{~mL}$ of the filtrate was subsampled for determination of $\mathrm{NH}_{3}$ and VFA concentrations. The subsamples were added with $3 \mathrm{~mL}$ of $25 \%$ metaphosphoric acid and with $3 \mathrm{~mL}$ of $0.6 \%$ 2-ethyl butyric acid as an internal standard and stored at $-20^{\circ} \mathrm{C}$ until analyses.

\section{Sample Collection, Measurements, and Laboratory Analyses}

One sample of the basal lactating cow TMR was collected weekly and stored at $-20^{\circ} \mathrm{C}$ for further $\mathrm{DM}$ and chemical analysis. Feed intake for each cow was recorded daily and adjusted for DM percentage (measured at $55^{\circ} \mathrm{C}$ ) of the weekly TMR to calculate DMI. Body weight and milk yield were recorded at each milking. Milk from each cow was sampled from 2 consecutive milkings on d 13 of each experimental period. Evening and morning samples were analyzed separately to allow for adjustments resulting from differing yields between the evening and morning milking.

Samples of the stored TMR were thawed at room temperature and dried for $48 \mathrm{~h}$ at $55^{\circ} \mathrm{C}$ in a forced-air oven and ground in a Wiley mill (Arthur H. Thomas, Philadelphia, PA) through a 1-mm screen. Samples of the ground TMR were composited by period and analyzed for analytical DM, CP, soluble CP, ADF, NDF, fat, and minerals using wet chemistry (Cumberland Valley Analytical Services Inc., Maugansville, MD; Table 1). Analytical DM was determined by drying at $135^{\circ} \mathrm{C}$ for $2 \mathrm{~h}$ (method 930.15; AOAC, 2005). Nitrogen was determined by combustion (method 990.03; AOAC, 2005; Leco FP-528 Combustion Analyzer; Leco Instruments Inc., St. Joseph, MI) and multiplied by 6.25 to obtain CP. Soluble CP was determined using a boratesodium phosphate buffer procedure (Roe and Sniffen, 1990). Acid detergent fiber and NDF were determined using the Ankom A200 Filter Bag Technique (Ankom Technology, Macedon, NY) according to Van Soest et al. (1991), with heat-stable amylase and sodium sulfite used in the NDF procedure. Fat was determined by using a Soxtec system (Tecator Soxtec System HT 1043 Extraction Unit; Tecator, Eden Prairie, MN; method 2003.05; AOAC, 2005). Minerals were determined using Perkin-Elmer 3300 XL and 5300 DV inductively coupled plasma instruments (Perkin-Elmer, Shelton, CT) with modifications (method 985.01; AOAC, 2000).

Milk samples were analyzed by Pennsylvania DHIA (University Park, PA) for content of fat, true protein, lactose, and MUN by using an infrared spectroscopic method (method 927.16; AOAC, 2005; MilkoScan 4000,
Foss Electric, Hillerød, Denmark). Plasma glucose concentration was measured according to the method of Trinder (1969; Enzymatic Glucose Kit 1075; Stanbio Laboratory Inc., Boerne, TX). Serum insulin concentration was measured using an RIA (Coat-A-Count Insulin Kit, number TKINX; Diagnostic Products Corp., Los Angeles, CA). Inter- and intraassay coefficients of variation for the insulin RIA were 6.2 and $22.3 \%$, respectively. Ruminal fluids were thawed and centrifuged at $3,000 \times g$ for $30 \mathrm{~min}$ at $4^{\circ} \mathrm{C}$, and the supernatants were retained and recentrifuged before analysis for $\mathrm{NH}_{3}$ (Broderick and Kang, 1980) and VFA (Yang and Varga, 1989).

\section{Calculations and Statistical Analyses}

Net energy balance was calculated for each cow per period according to the method of Chung et al. (2007). The additional energy provided by PG was included in net energy intake. Daily measurements of DMI, BW, and milk yield that were recorded from d 11 to 14 when treatments were administrated were averaged by period before statistical analysis. For serial serum insulin and plasma glucose concentrations obtained during each of the sampling periods, geometric means were calculated (areas under the curve divided by the sampling time length) to account for unequally spaced measurements; for serial ruminal characteristics, observational means were calculated because of equally spaced measurements. Maximum responses (compared with the measurement at time 0) of serum insulin and plasma glucose to PG supplementation and time required for insulin and glucose to reach the peak responses during the serial sampling period were identified for each cow at each period, and means were calculated by treatment (Matthews et al., 1990). Dependent variables were analyzed by using PROC MIXED (SAS Institute, 1999), and the general linear mixed model included the fixed effects of square, treatment (methods of delivery), and period within each square. Cow nested within square was used in the RANDOM statement. Denominator degrees of freedom were estimated using the Kenward-Roger option in the MODEL statement. The PDIFF option adjusted by the Tukey method was used for multiple-comparison tests between delivery methods. A comparison between with-PG supplementation (dietary, oral-drench, and rumen-drench treatments) or without-PG supplementation (control treatment) was preplanned. The time trends for serial rumen measurements and serum insulin and plasma glucose concentrations were analyzed as repeated measures by using PROC MIXED (SAS Institute, 1999), and the general linear mixed model included the fixed effects of treatment (methods of delivery), sampling time, and their interaction. Time 
Table 2. Dry matter intake, milk yield, and energy balance for cows receiving propylene glycol (PG) as a part of the TMR (dietary treatment), as an oral drench (oral-drench treatment), or as a rumen drench (rumen-drench treatment)

\begin{tabular}{|c|c|c|c|c|c|c|c|}
\hline \multirow[b]{2}{*}{ Variable } & \multicolumn{4}{|c|}{ Treatment $^{1}$} & \multirow[b]{2}{*}{ SEM } & \multicolumn{2}{|c|}{ Effect or contrast, ${ }^{2} P$-value } \\
\hline & Control & Dietary & Oral drench & Rumen drench & & Treatment & Control vs. PG \\
\hline $\mathrm{BW}^{3} \mathrm{~kg}$ & 708 & 701 & 703 & 695 & 27.48 & 0.40 & 0.18 \\
\hline $\mathrm{DMI},{ }^{3} \%$ of $\mathrm{BW}$ & 3.61 & 3.54 & 3.59 & 3.52 & 0.18 & 0.84 & 0.56 \\
\hline Milk yield, ${ }^{3} \mathrm{~kg} / \mathrm{d}$ & 39.0 & 38.9 & 39.6 & 37.7 & 3.28 & 0.25 & 0.77 \\
\hline $3.5 \% \mathrm{FCM},{ }^{4,5} \mathrm{~kg} / \mathrm{d}$ & 36.5 & 35.1 & 39.1 & 37.8 & 3.81 & 0.53 & 0.72 \\
\hline Energy balance, ${ }^{5} \mathrm{Mcal} / \mathrm{d}$ & 5.38 & 5.86 & 3.39 & 3.60 & 1.82 & 0.40 & 0.45 \\
\hline
\end{tabular}

${ }^{1}$ Treatments: control $=$ no $\mathrm{PG}$; dietary $=200 \mathrm{~g} / \mathrm{d}$ of PG as a dry product $(65 \%$ purity; corresponded to $308 \mathrm{~g} / \mathrm{d}$ of the dry product) mixed into the TMR; oral drench $=200 \mathrm{~mL} / \mathrm{d}$ of liquid PG (100\% purity) orally drenched; rumen drench $=200 \mathrm{~g} / \mathrm{d}$ of PG as a dry product drenched via the rumen cannula.

${ }^{2}$ Treatment $=$ comparisons among delivery methods; control vs. PG = comparison of no PG (control) with PG (dietary, oral drench, and rumen drench).

${ }^{3}$ Data were averaged from d 11 to 14 of each experimental period (treatment period).

${ }^{4} 3.5 \% \mathrm{FCM}$ yield $=(0.4255 \times$ milk yield $)+[16.425 \times(\%$ fat $\div 100) \times$ milk yield $] ; 3.5 \% \mathrm{FCM}$ efficiency $=\mathrm{kg}$ of $3.5 \% \mathrm{FCM} \div \mathrm{kg}$ of $\mathrm{DMI}$.

${ }^{5}$ Calculated once for each cow per period. Energy balance $=\left[\mathrm{NE}_{\mathrm{I}} \div\left(\mathrm{NE}_{\mathrm{M}}+\mathrm{NE}_{\mathrm{L}}\right)\right]$ as $\mathrm{Mcal} / \mathrm{d}$ or $\left[\mathrm{NE}_{\mathrm{I}} \div\left(\mathrm{NE}_{\mathrm{M}}+\mathrm{NE}_{\mathrm{L}}\right) \times 100\right]$ as a percentage of the requirement. Net energy intake $\left(\mathrm{NE}_{\mathrm{I}}\right)=\mathrm{DMI} \times$ dietary $\mathrm{NE}_{\mathrm{L}}+\mathrm{NE}_{\mathrm{L}}$ from $\mathrm{PG}$. $\mathrm{NE}_{\mathrm{M}}=\mathrm{BW}$ $\times$ fat $\%)+(0.0563 \times$ protein $\%)+(0.0395 \times$ lactose $\%)]$.

of sampling was used in the REPEATED statement. Time-series covariance structure was modeled using the options of autoregressive order one, compound symmetry, unstructured, and spatial power. The best timeseries covariance structure was selected based on the lowest Akaike and Bayesian information criteria. Data are presented as means \pm standard deviations or least squares means \pm standard errors or standard errors of the means. Statistical significance was declared at $P \leq$ 0.05 and a tendency to significance was declared at 0.05 $<P \leq 0.10$.

\section{RESULTS}

Supplementing lactating cow diets with $\mathrm{PG}$, regardless of the delivery method, did not affect DMI, BW, milk yield, 3.5\% FCM yield and efficiency, energy balance (Table 2), or milk composition (Table 3), except for milk lactose percentage. Percentages of milk lactose were increased by PG for all delivery methods (treatment effect: $P=0.05$; control vs. PG: $P<0.01$ ); however, yields of milk lactose were not significantly affected by PG.

Dry matter intake and ruminal characteristics for 4 $\mathrm{h}$ after PG administration are reported in Table 4. Dry matter intakes during the 4-h serial sampling period after PG administration were similar among treatments. Ruminal pH (treatment effect: $P=0.02$ ), $\mathrm{NH}_{3}$ concentration (treatment effect: $P<0.01$; control vs. PG: $P=0.02$ ), and individual VFA concentrations as percentages of total VFA were affected by PG supplementation, delivery methods for PG, or both. Total VFA concentrations, however, were similar among treatments. Concentrations of acetate were decreased and concentrations of propionate and isovalerate were increased by $\mathrm{PG}$ supplementation, regardless of the delivery method (treatment effect: $P<0.01$; control vs. PG: $P<0.01)$. Concentrations of butyrate were decreased (treatment effect: $P=0.05$; control vs. PG: $P=$ 0.01 ) and valerate was increased (treatment effect: $P<$

Table 3. Percentages and yields of milk components for cows receiving propylene glycol (PG) as a part of the TMR (dietary treatment), as an oral drench (oral-drench treatment), or as a rumen drench (rumen-drench treatment)

\begin{tabular}{|c|c|c|c|c|c|c|c|}
\hline Variable $^{1}$ & \multicolumn{4}{|c|}{ Treatment } & SEM & \multicolumn{2}{|c|}{ Effect or contrast, $P$-value } \\
\hline Fat, $\%$ & 3.68 & 3.41 & 3.60 & 3.43 & 0.22 & 0.47 & 0.20 \\
\hline Protein, \% & 3.07 & 3.07 & 3.08 & 3.05 & 0.09 & 0.83 & 0.79 \\
\hline Protein yield, kg/d & 1.08 & 1.07 & 1.18 & 1.15 & 0.08 & 0.28 & 0.34 \\
\hline Lactose, \% & 4.63 & 4.73 & 4.72 & 4.72 & 0.08 & 0.05 & $<0.01$ \\
\hline
\end{tabular}

${ }^{1}$ Data were averaged from 2 consecutive milkings sampled on d 13. 
Table 4. Dry matter intake and rumen characteristics of cows for $4 \mathrm{~h}$ after receiving propylene glycol (PG) as a part of the TMR (dietary treatment), as an oral drench (oral-drench treatment), or as a rumen drench (rumen-drench treatment)

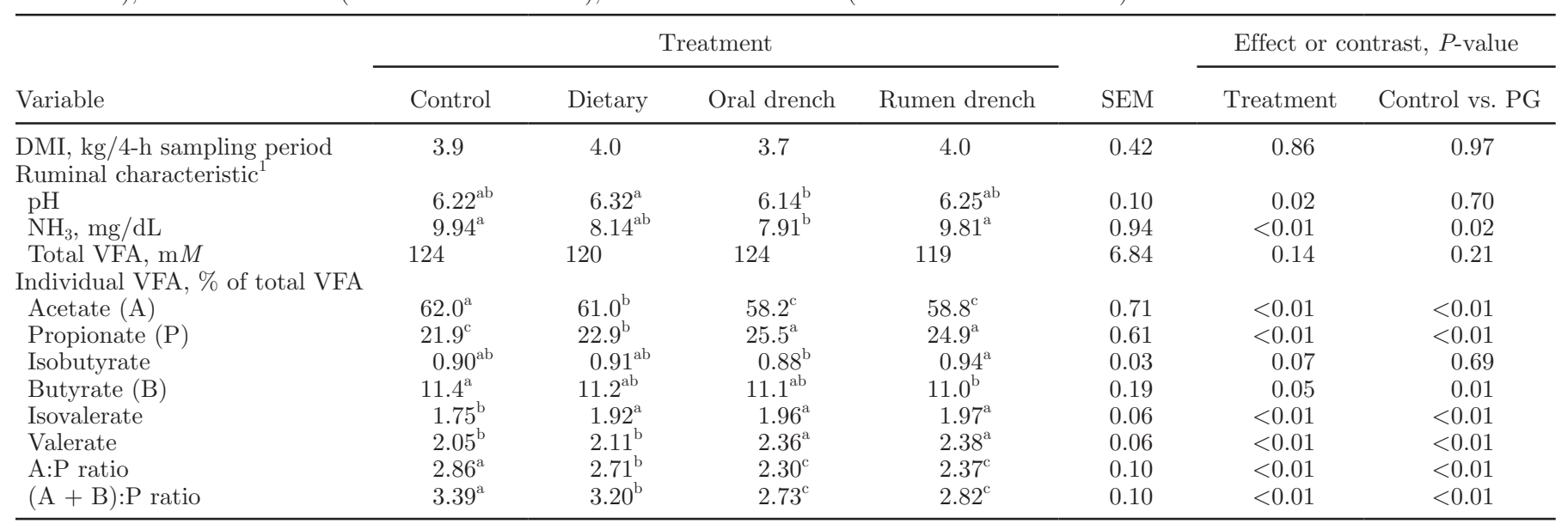

${ }^{\mathrm{a}-\mathrm{C}}$ Within a row, means that do not have a common superscript differ, $P \leq 0.05$.

${ }^{1}$ Data were averaged from the 4 sampling time points over the 4-h period (on $\mathrm{d} 14$ ).

0.01; control vs. PG: $P<0.01)$ by PG supplementation via drenching orally or ruminally, but not via feeding. Cows receiving PG as an oral or ruminal drench had the lowest acetate-to-propionate ratios and the lowest ketogenic (acetate plus butyrate)-to-glucogenic (propionate) ratios, followed by cows receiving $\mathrm{PG}$ as a part of the TMR and control cows (treatment effect: $P<$ 0.01; control vs. PG: $P<0.01$ ).

Serum insulin and plasma glucose concentrations for 4 $\mathrm{h}$ after PG administration are reported in Table 5. During the 4-h serial sampling period after PG supplementation, mean serum insulin concentration was increased (treatment effect: $P<0.01$; control vs. PG: $P=0.02$ ) by both oral and ruminal drenching of PG. Concentrations of serum insulin for cows receiving $\mathrm{PG}$ as an oral or ruminal drench peaked higher (treatment effect: $P$ $<0.01$; control vs. PG: $P<0.01)$ and more rapidly (treatment effect: $P<0.01$; control vs. PG: $P=0.09$ ) than for cows receiving $P G$ as a part of the TMR or for control cows. Unlike serum insulin, mean plasma glucose concentrations tended (control vs. PG: $P=0.09$ ) to be greater for cows receiving $\mathrm{PG}$ supplementation than for control cows regardless of the delivery method. Concentrations of plasma glucose for PG-supplemented cows also tended to peak higher (control vs. PG effect: $P=0.06$ ) and more rapidly (control vs. PG effect: $P=$ 0.06 ) than for control cows. Serum insulin and plasma glucose concentrations were similar among treatments immediately before the administration of treatments (baseline).

\section{DISCUSSION}

Propylene glycol, in either liquid or dry form in the current study, shifted ruminal VFA patterns toward a more glucogenic environment without affecting ruminal fermentation and ruminal $\mathrm{NH}_{3}$ availability. Ruminal $\mathrm{pH}$ observed in the current study at any sampling time points ranged from 6.05 to 6.45 , which was within the normal range for ruminal $\mathrm{pH}$ from 5.8 to 6.8 (Bergman, $1990)$ and was above the $\mathrm{pH}$ level $(<5.5)$ that can cause subclinical ruminal acidosis (Nocek, 1997). A decrease in $\mathrm{pH}$ could have been expected because of an increase in propionate concentration in the rumen from ruminal fermentation of PG, as suggested by Nielsen and Ingvartsen (2004). The effect of PG on ruminal $\mathrm{pH}$, however, was not consistent in the current study. During the 4-h serial sampling period, only cows receiving PG as an oral drench consistently had lower ruminal $\mathrm{pH}$ compared with all other treatments. The amount (200 $\mathrm{mL}$ or $200 \mathrm{~g} / \mathrm{d}$ ) of $\mathrm{PG}$ drenched or fed in the current study was equal to or less than the amounts of PG used in other studies (Dhiman et al., 1993; Cozzi et al., 1996; Shingfield et al., 2002; PG ranged from 200 to $688 \mathrm{~g} / \mathrm{d}$ ), in which no effects of $\mathrm{PG}$ were found on ruminal $\mathrm{pH}$ for cows in midlactation. An explanation for the lack of effects of $\mathrm{PG}$ on ruminal $\mathrm{pH}$ observed in the studies mentioned previously was suggested to be related to the lack of effects of PG on ruminal total VFA production (Nielsen and Ingvartsen, 2004). A potential reduction in ruminal $\mathrm{pH}$ because of $\mathrm{PG}$ may negatively influence ruminal fermentation when cows have low ruminal $\mathrm{pH}$, such as conditions of high starch load in the diet or inadequate effective fiber from forage.

Propylene glycol did not seem to have an effect on ruminal $\mathrm{NH}_{3}$ availability. In the current experiment, although cows receiving liquid $\mathrm{PG}$ as an oral drench had the lowest ruminal $\mathrm{NH}_{3}$ concentration, cows receiving dry $\mathrm{PG}$ as a rumen drench had a ruminal $\mathrm{NH}_{3}$ concentration similar to the control cows or the cows receiving dry $\mathrm{PG}$ from the diet. These comparable 
Table 5. Serum insulin and plasma glucose concentrations of cows for $4 \mathrm{~h}$ after receiving propylene glycol (PG) as a part of the TMR (dietary treatment), as an oral drench (oral-drench treatment), or as a rumen drench (rumen-drench treatment)

\begin{tabular}{|c|c|c|c|c|c|c|c|}
\hline Variable $^{1}$ & Control & Dietary & Oral drench & Rumen drench & SEM & Treatment & Control vs. PG \\
\hline Mean $^{2}$ & $134^{\mathrm{b}}$ & $129^{\mathrm{b}}$ & $242^{\mathrm{a}}$ & $217^{\mathrm{a}}$ & 37.25 & $<0.01$ & 0.02 \\
\hline Maximum $^{3}$ & $164^{\mathrm{b}}$ & $152^{\mathrm{b}}$ & $439^{\mathrm{a}}$ & $407^{\mathrm{a}}$ & 58.64 & $<0.01$ & $<0.01$ \\
\hline Time to reach the maximum, ${ }^{4} \min$ & $108^{\mathrm{ab}}$ & $130^{\mathrm{a}}$ & $36^{\mathrm{b}}$ & $26^{\mathrm{b}}$ & 23.59 & $<0.01$ & 0.09 \\
\hline Baseline $^{1}$ & 108 & 115 & 97 & 104 & 24.95 & 0.87 & 0.86 \\
\hline Maximum $^{3}$ & 78.3 & 81.0 & 81.3 & 82.7 & 1.60 & 0.22 & 0.06 \\
\hline Time to reach the maximum, ${ }^{4}$ min & 136 & 88 & 96 & 50 & 25.05 & 0.15 & 0.06 \\
\hline Baseline $^{1}$ & 67.8 & 70.8 & 68.9 & 69.3 & 1.53 & 0.39 & 0.20 \\
\hline
\end{tabular}

${ }^{\mathrm{a}, \mathrm{b}}$ Within a row, means that do not have a common superscript differ, $P \leq 0.05$.

${ }^{1}$ Jugular blood was sampled immediately before (baseline) and immediately after (time 0 ) the administration of treatments and at 10-min intervals for the first hour and at 20-min intervals for an additional $3 \mathrm{~h}$ (total of 17 time points).

${ }^{2}$ Data were averaged from the 17 sampling time points over the 4 -h period. Geometric mean = areas under the curve $\div$ sampling time length.

${ }^{3}$ The maximum response from time 0 .

${ }^{4}$ Time required to reach the maximal level from time 0 .

concentrations of ruminal $\mathrm{NH}_{3}$ and the similar $\mathrm{MUN}$ between treatments suggested that the lower ruminal $\mathrm{NH}_{3}$ concentration observed in orally drenched cows was likely not affected by $\mathrm{PG}$. Ruminal $\mathrm{NH}_{3}$ concentrations observed in the current study at any sampling time points exceeded the concentration of $5 \mathrm{mg} / \mathrm{dL}$ that was determined to maximize microbial efficiency in continuous culture (Satter and Slyter, 1974). Ammonia is the major $\mathrm{N}$ source for the growth of many rumen bacterial species (Bryant, 1974). The ruminal $\mathrm{NH}_{3}$ concentrations obtained in the current study could likely indicate that the ruminal $\mathrm{N}$ availability was not limited or affected by $\mathrm{PG}$ for the maximal rate of synthesis and yield of microbial protein, at least for the amount (200 g or $200 \mathrm{~mL} / \mathrm{d}$ ) of PG supplemented and in the time frame monitored (4 $\mathrm{h}$ after administration).

Propylene glycol appeared to shift ruminal VFA patterns by producing more glucogenic VFA, such as propionate (Figure 1) and valerate, at the expense of lipogenic VFA, such as acetate (Figure 2). The effect of PG on ketogenic VFA, such as butyrate, seemed to be inconsistent and relatively small compared with the effect of PG on propionate and acetate (Nielsen and Ingvartsen, 2004). The inconsistent effect of PG on butyrate may be related to the type of diet fed and the amounts of PG infused. Propionate can provide a minimum of $50 \%$ to a maximum of $75 \%$ of the glucose requirement in ruminants (Bergman, 1990). Valerate and isobutyrate can provide carbon sources for glucose biosynthesis and thus are considered to be glucogenic, although their contributions to gluconeogenesis are relatively small compared with propionate (Leng, 1970). The relative proportion of propionate to total VFA on a molar basis is approximately $20 \%$ and that of valerate and isobutyrate combined is 2 to $4 \%$; therefore, approximately $25 \%$ of total VFA are glucogenic. In the current study, the total glucogenic VFA was increased from $24.9 \%$ for cows receiving no PG to 25.9, 28.8, and $28.3 \%$ for cows receiving PG mixed into the TMR, as an oral drench, and as a ruminal drench, respectively. It is obvious that $200 \mathrm{~mL}$ or $200 \mathrm{~g}$ of $\mathrm{PG}$, in either liquid or dry form, by drenching shifted ruminal VFA patterns; however, PG as a dry product mixed into the TMR at as little as $24.4 \mathrm{~g} / \mathrm{cow}( \pm 2.4 \mathrm{SE}$; the average amount of PG consumed during the 4-h sampling period) could also affect ruminal VFA patterns.

In the current experiment, postprandial effects appeared to be minimized by $12 \times$ feeding/d, as indicated by minimal fluctuations in serum insulin concentrations observed in the control cows (Figure 3). Based on the assumption made by Armentano et al. (1984) that cattle fed $12 \times$ feeding/d were in a steady state for glucose production and utilization, any responses observed in blood glucose could therefore be attributed to treatments. Plasma glucose was tightly regulated in a narrow range; however, in the current study, the mean plasma glucose levels were numerically greater for the PG-supplemented cows than for the control cows, which could indicate that PG, its metabolite(s), or both affected glucose production, utilization, or both. Kristensen and Raun (2007) suggested that glucose utilization, rather than glucose production, was affected by PG, its metabolite(s), or both because glucose production was not increased in cows infused with PG (Palmquist and Brunengraber, 1997; Kristensen and Raun, 2007). An increase in plasma glucose concentration after PG 


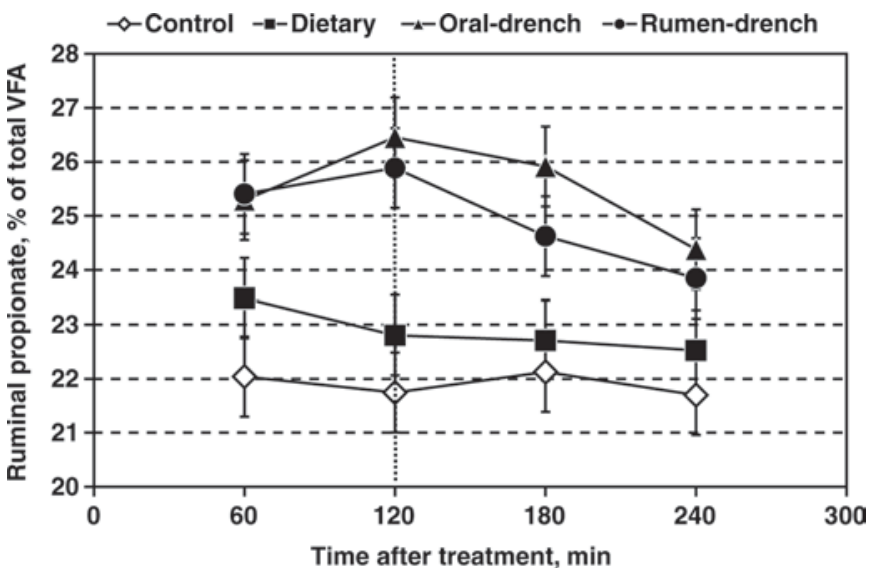

Figure 1. Ruminal propionate concentrations of cows (fed at $12 \times$ feeding/d) for $4 \mathrm{~h}$ after receiving propylene glycol mixed into the TMR (dietary treatment), as an oral drench (oral-drench treatment), or as a ruminal drench (rumen-drench treatment). Pooled SEM $=0.77$; treatment (delivery method) effect: $P<0.01$; time effect: $P<0.01$; treatment $\times$ time interaction: $P<0.01$. The dotted vertical line indicates feeding.

infusion was due to a decrease in glucose utilization by peripheral tissues, even under increased serum insulin concentrations (Kristensen and Raun, 2007). This insulin-resistant-like effect on peripheral tissues was likely induced by an increased concentration of PG and propanol, a decreased ratio of ketogenic to glucogenic metabolites in the blood from PG metabolism, or both (Kristensen and Raun, 2007). Responses of insulin, similar to the responses of ruminal VFA, to PG supplementation were greater for the oral or ruminal drench of PG compared with mixing PG into the TMR, likely because of the amount of PG that was available to the rumen of the animal at the time of sampling. A relatively large amount of propionate produced from ruminal metabolism of PG could saturate the liver, thereby escaping hepatic removal and stimulating a pancreatic release of insulin. In the current study, by feeding cows frequently, at $12 \times$ feeding/d, to minimize postprandial effects caused by feeding, oral or ruminal drenching of $200 \mathrm{~mL}$ or $200 \mathrm{~g} / \mathrm{d}$ of PG increased the insulin level by 169 and 195\% (from the level at time 0 to the maximal level), respectively, as opposed to the $102 \%$ observed in our previous experiment (Chung et al., 2009). Oral or ruminal drenching of $\mathrm{PG}$ in the current study also increased the mean insulin concentration during the serial sampling period, as opposed to our previous experiment (Chung et al., 2009) in which the mean insulin concentration was not increased by PG top dressing, although a pattern of insulin response similar to that in the current study was observed. When a bolus dose of PG was provided to cows, the discrepancy in increased insulin concentration between the current study (oral and ruminal drenching) and our previous experiment (top dressing) indicated that an effect of PG on insulin was perhaps masked by feed intake (cows were fed $1 \times$ feeding/d in our pervious experiment).

Supplementing diets with PG tended to increase milk yield and reduce milk fat percentage for cows in early lactation, as summarized in a review by Nielsen and Ingvartsen (2004); however, an effect of PG on other milk components was not consistent in the literature. In the current study, milk yield was not affected by $\mathrm{PG}$, and a clear reduction in milk fat percentage by PG was not evident. Fisher et al. (1973) reported a 0.2 -percentage-unit increase in milk lactose percentage by feeding $495 \mathrm{~g} / \mathrm{d}$ of PG to cows in early lactation, whereas feeding 178 to $260 \mathrm{~g} / \mathrm{d}$ had no effects on milk lactose. Cozzi et al. (1996) and Shingfield et al. (2002) reported no effects of PG on milk lactose by feeding 200 to $400 \mathrm{~g} / \mathrm{d}$ of $\mathrm{PG}$ to cows in midlactation. Supplementation of PG from $161( \pm 4.1 \mathrm{SE}$; the average amount of PG that was consumed daily from TMR) to $200 \mathrm{~g} / \mathrm{d}$ (drenched orally or ruminally), regardless of the delivery method, increased milk lactose percentage in the current experiment. A possible explanation for an increase in milk lactose percentage is an insulinresistant-like effect on peripheral tissues induced by PG (Kristensen and Raun, 2007), as discussed previously. An increased concentration of blood PG and propanol, a decreased ratio of ketogenic to glucogenic metabolites in the blood from PG metabolism, or both can decrease glucose utilization by peripheral tissues; therefore, more glucose can be partitioned to the mammary gland for milk lactose synthesis.

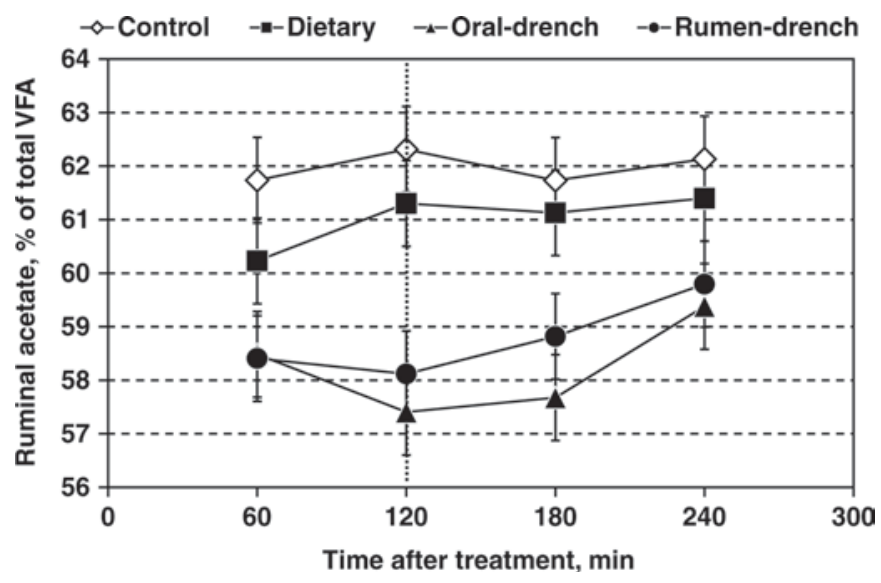

Figure 2. Ruminal acetate concentrations of cows (fed at $12 \times$ feeding/d) for $4 \mathrm{~h}$ after receiving propylene glycol mixed into the TMR (dietary treatment), as an oral drench (oral-drench treatment), or as a ruminal drench (rumen-drench treatment). Pooled SEM = 0.83. Treatment (delivery method) effect: $P<0.01$; time effect: $P<$ 0.01 ; treatment $\times$ time interaction: $P<0.01$. The dotted vertical line indicates feeding. 


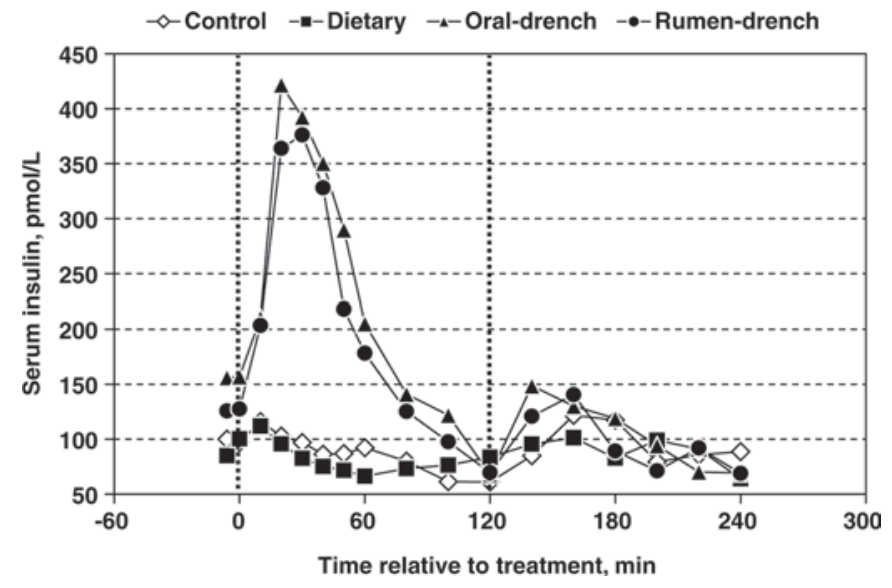

Figure 3. Serum insulin concentrations of cows (fed at $12 \times$ feeding/d) for $4 \mathrm{~h}$ after receiving propylene glycol mixed into the TMR (dietary treatment), as an oral drench (oral-drench treatment), or as a ruminal drench (rumen-drench treatment). Pooled SEM = 33.1. Treatment (delivery method) effect: $P<0.01$; time effect: $P<$ 0.01; treatment $\times$ time interaction: $P<0.01$. The dotted vertical lines indicate feeding.

Drenching PG by using an esophageal-stomach tube or a drench gun, as opposed to feeding PG, could likely lead to a greater portion of $P G$ bypassing the rumen because of the closure of the reticular groove while drenching. However, in the current study, oral drenching of PG had a similar effect in stimulating insulin to rumen drenching of PG. It was likely that some of the PG by rumen drenching also bypassed the rumen through the reticular-omasal orifice. Christensen et al. (1997) reported that the ability of PG administered via oral drenching to increase serum insulin and decrease plasma NEFA concentrations was comparable with feeding PG in the concentrate. This similar glucogenic capacity of PG between drenching and bolus feeding (e.g., top dressing or feeding PG in the concentrate and fed separately from forage) could probably be explained by the diffusion of $\mathrm{PG}$ from the bloodstream into the rumen (Raun et al., 2004) after the PG that bypasses the rumen is absorbed from the lumen of the small intestines. Propylene glycol, as a dry form drenched into the cavity of the reticulum via the rumen cannula, was as effective as liquid PG drenched via the mouth in shifting ruminal VFA profiles and stimulating blood insulin and glucose responses.

\section{CONCLUSIONS}

Oral drenching of $200 \mathrm{~mL}$ of liquid PG or rumen drenching of $200 \mathrm{~g}$ of $\mathrm{PG}$ as a dry product shifted ruminal fermentation toward a more glucogenic environment and increased serum concentration of insulin. Feeding dry $\mathrm{PG}$ as a part of the diet (incorporating dry PG into the diet) was not as effective as drenching PG. Dry matter intake, BW, and milk yield and composition, except for milk lactose percentage, were not affected by PG supplementation. Effects of drenching dry PG into the rumen were comparable with orally drenching liquid PG.

\section{ACKNOWLEDGMENTS}

We thank L. Griel Jr. and J. Werner for performing jugular catheterization and A. Martinez, M. White, J. Peters, and S. Costa for sampling (all of Penn State); N. Houck, T. Edwards, B. Homan, D. Hawn, and the staff at the Pennsylvania State University Dairy Cattle Research and Education Center (University Park, PA) for feeding and constant care of the cows; and A. Ames (NutriLinx LLC, Montpelier, VT) for providing the PG.

\section{REFERENCES}

AOAC. 2000. Official Methods of Analysis. 17th ed. AOAC Int., Gaithersburg, MD.

AOAC. 2005. Official Methods of Analysis. 18th ed. AOAC Int., Gaithersburg, MD.

Armentano, L. E., S. E. Mills, G. deBoer, and J. W. Young. 1984. Effects of feeding frequency on glucose concentration, glucose turnover, and insulin concentration in steers. J. Dairy Sci. $67: 1445-1451$.

Bassett, J. M. 1975. Dietary and gastro-intestinal control of hormones regulating carbohydrate metabolism in ruminants. Pages 383-398 in Digestion and Metabolism in the Ruminant. I. W. McDonald and A. C. I. Warner, ed., Univ. New England Publ. Unit., Sydney, Australia.

Bergman, E. N. 1990. Energy contributions of volatile fatty acids from the gastrointestinal tract in various species. Physiol. Rev. 70:567-590.

Broderick, G. A., and J. H. Kang. 1980. Automated simulaneous determination of ammonia and total amino acids in ruminal fluid and in vitro media. J. Dairy Sci. 63:64-75.

Bryant, M. P. 1974. Nutritional features and ecology of predominant anaerobic bacteria of the intestinal tract. Am. J. Clin. Nutr. 27:1313-1319.

Christensen, J. O., R. R. Grummer, F. E. Rasmussen, and S. J. Bertics. 1997. Effect of method of delivery of propylene glycol on plasma metabolites of feed-restricted cattle. J. Dairy Sci. 80:563-568.

Chung, Y.-H., N. E. Brown, C. M. Martinez, T. W. Cassidy, and G. A. Varga. 2009a. Effects of rumen-protected choline and dry propylene glycol on feed intake and blood parameters for Holstein dairy cows in early lactation. J. Dairy Sci. 92:2729-2736.

Chung, Y.-H., I. D. Girard, and G. A. Varga. 2009b. Effects of feeding dry propylene glycol to early postpartum Holstein dairy cows on production and blood parameters. Animal In press.

Chung, Y.-H., D. E. Rico, C. M. Martinez, T. W. Cassidy, V. Noirot, A. Ames, and G. A. Varga. 2007. Effects of feeding dry glycerin to early postpartum Holstein dairy cows on lactational performance and metabolic profiles. J. Dairy Sci. 90:5682-5691.

Clapperton, J. L., and J. W. Czerkawski. 1972. Metabolism of propane-1:2-diol infused into the rumen of sheep. Br. J. Nutr. $27: 553-560$.

Cozzi, G., P. Berzaghi, F. Gottardo, G. Gabai, and I. Andrighetto. 1996. Effects of feeding propylene glycol to mid-lactating dairy cows. Anim. Feed Sci. Technol. 64:43-51.

Czerkawski, J. W., and G. Breckenridge. 1972. Fermentation of various glycolytic intermediates and other compounds by rumen micro- 
organisms, with particular reference to methane production. Br. J. Nutr. 27:131-146.

Dhiman, T. R., C. Cadorniga, and L. D. Salter. 1993. Protein and energy supplementation of high alfalfa silage diets during early lactation. J. Dairy Sci. 76:1945-1959.

Fisher, L. J., J. D. Erfle, G. A. Lodge, and F. D. Sauer. 1973. Effects of propylene glycol or glycerol supplementation of the diet of dairy cows on feed intake, milk yield and composition, and incidence of ketosis. Can. J. Anim. Sci. 53:289-296.

Grummer, R. R., J. C. Winkler, S. J. Bertics, and V. A. Studer. 1994. Effect of propylene glycol dosage during feed restriction on metabolites in blood of prepartum Holstein heifers. J. Dairy Sci. 77:3618-3623.

Hanzlik, P. J., A. J. Lehman, W. Van Winkle Jr., and N. K. Kennedy. 1939. General metabolic and glycohenic actions of propylene glycol and some other glycols. J. Pharmacol. Exp. Ther. 67:114-126.

Herdt, T. H., and R. S. Emery. 1992. Therapy of diseases of ruminant intermediary metabolism. Vet. Clin. North Am. Food Anim. Pract. 8:91-106.

Johnson, R. B. 1954. The treatment of ketosis with glycerol and propylene glycol. Cornell Vet. 44:6-21.

Kristensen, N. B., and B. M. Raun. 2007. Ruminal and intermediary metabolism of propylene glycol in lactating Holstein cows. J. Dairy Sci. 90:4707-4717.

Leng, R. A. 1970. Glucose synthesis in ruminants. Pages 209-260 in Advances in Veterinary Science and Comparative Medicine. C. A. Brandly and C. E. Cornelius, ed. Academic Press, New York, NY

Matthews, J. N. S., D. G. Altman, M. J. Campbell, and P. Royston. 1990. Analysis of serial measurements in medical research. Br. Med. J. 300:230-235.

Nielsen, N. I., and K. L. Ingvartsen. 2004. Propylene glycol for dairy cows: A review of the metabolism of propylene glycol and its effects on physiological parameters, feed intake, milk production and risk of ketosis. Anim. Feed Sci. Technol. 115:191-213.

Nocek, J. E. 1997. Bovine acidosis: Implications on laminitis. J. Dairy Sci. 80:1005-1028.
NRC. 2001. Nutrient Requirements of Dairy Cattle. 7th rev. ed. Natl. Acad. Sci., Washington, DC.

Palmquist, D. L., and H. Brunengraber. 1997. Role of 1,2-propanediol in ruminant glucose metabolism. Pages $115-118$ in Energy Metabolism on Farm Animals. K. J. McCracken, E. F. Unsworth, and A. R. G. Wylie, ed. CAB International, Wallingford, UK.

Raun, B. M. L., N. B. Kristensen, and D. L. Harmon. 2004. Splanchnic metabolism of propylene glycol infused into the jugular vein of steers under washed rumen conditions. J. Anim. Feed Sci. 13(Suppl. 1):331-334.

Roe, M. B., and C. J. Sniffen. 1990. Techniques for measuring protein fractions in feedstuffs. Pages 81-88 in Proc. Cornell Nutr. Conf. Feed Manuf. Cornell Univ., Ithaca, NY.

SAS Institute. 1999. SAS/STAT User's Guide: Statistics, Version 8 Edition. SAS Inst. Inc., Cary, NC.

Satter, L. D., and L. L. Slyter. 1974. Effect of ammonia concentration of rumen microbial protein production in vitro. Br. J. Nutr. 32:199-208.

Shingfield, K. J., S. Jaakkola, and P. Huhtanen. 2002. Effect of forage conservation method, concentrate level and propylene glycol on diet digestibility, rumen fermentation, blood metabolite concentrations and nutrient utilisation of dairy cows. Anim. Feed Sci. Technol. 97:1-21.

Studer, V. A., R. R. Grummer, S. J. Bertics, and C. K. Reynolds. 1993. Effect of prepartum propylene glycol administration on periparturient fatty liver in dairy cows. J. Dairy Sci. 76:29312939

Trinder, P. 1969. Determination of glucose in blood using glucose oxidase with an alternative oxygen acceptor. Ann. Clin. Biochem. 6:24-27.

Van Soest, P. J., J. B. Robertson, and B. A. Lewis. 1991. Methods for dietary fiber, neutral detergent fiber, and nonstarch polysaccharides in relation to animal nutrition. J. Dairy Sci. 74:3583-3597.

Yang, C.-M. Jr., and G. A. Varga. 1989. Effect of three concentrate feeding frequencies on rumen protozoa, rumen digesta kinetics, and milk yield in dairy cows. J. Dairy Sci. 72:950-957. 